\title{
DEVELOPMENT OF A LOW-COST THIRD GENERATION SINGLE CRYSTAL SUPERALLOY DD9
}

\author{
J.R. Li, S.Z. Liu, X.G. Wang, Z.X. Shi and J.Q. Zhao \\ Science and Technology on Advanced High Temperature Structural Materials Laboratory, Beijing Institute of Aeronautical Materials; \\ P.O. Box 81-8; Beijing, 100095, P.R. China
}

Keywords: Third generation single crystal superalloy, DD9, Creep, Microstructure stability, Oxidation resistance

\begin{abstract}
Single crystal (SC) superalloys are widely used in the high pressure turbine section of aero gas turbine engines due to the unique combination of properties and performance, and alloy development has generally focused on increased temperature capability. A low-cost third generation single crystal superalloy, designated as DD9, has been developed for aeroengine turbine blade applications. DD9 alloy contains 4.5 wt. \% rhenium (Re), which is about $75 \%, 83 \%$ and $90 \%$ of the Re contents in the third generation single crystal superalloys CMSX-10, René N6 and TMS-75. The alloy system employs relatively high additions of refractory elements (tungsten, molybdenum, tantalum, rhenium and niobium) with contents of about 21 wt. \%.
\end{abstract}

DD9 alloy has an approximate $30{ }^{\circ} \mathrm{C}$ improvement of temperature capability relative to DD6 alloy, a Chinese second generation single crystal alloy with creep rupture properties that are comparable with PWA 1484, René N5 and CMSX-4. The tensile properties and creep rupture properties of DD9 alloy are comparable to those of the third generation single crystal alloys such as CMSX-10, René N6 and TMS-75. The advantage of DD9 alloy shown in the creep rupture properties over DD6 also generally holds for fatigue properties. DD9 alloy has good microstructure stability and heat treatment characteristics, and the alloy also provides superior oxidation resistance and hot corrosion resistance.

Casting trials have been conducted on DD9 involving a great number of bars, several different complex shaped hollow turbine blades and double wall cooling blades. It is shown that DD9 casting yields and grain structure are similar to the second generation single crystal superalloys. These trials demonstrate that DD9 alloy possesses excellent single crystal castability.

\section{Introduction}

Because single crystal superalloys offer improved creep rupture, fatigue, environmental and coating properties, resulting in superior turbine engine performance and durability, the application of single crystal turbine components increased remarkably in advanced propulsion systems [1-8]. The first and second generation single crystal superalloys have been widely used for commercial and military aeroengines since the 1980's [1,2,9-16]. Afterwards, the third generation single crystal superalloys have been developed and utilized [5, 6, 17-21], and the fourth generation single crystal superalloy has been developed [8]. Table I presents the nominal compositions of some typical first, second and third generation single crystal superalloys. A main characteristic of the chemical compositions of the first, second and third generation single crystal superalloys is rhenium- free, 3 wt.\% Re and 5-6 wt.\% Re, respectively. The effects of Re on the mechanical properties of single crystal superalloys are very important, especially for improving the creep rupture life at elevated temperature. However, Re is relatively rare element which leads to its very high price, and the aeroengine manufactures all consider Re as a strategic element. Therefore, the development of the second and third generation single crystal superalloys with lower Re content is important.

A low-cost second generation single crystal superalloy DD6 has been developed and widely used for aeroengine blade applications $[15,16]$, the alloy system employs a relatively high refractory element content of about 20 wt. $\%$ and contains 2 wt. \% Re. The Re content of DD6 alloy is about $2 / 3$ of that in other second generation single crystal superalloys such as PWA 1484, René N5 and CMSX-4 [2,13-16]. The creep strength of DD6 are equivalent to those of other second generation single crystal superalloys widely used in the world, such as PWA 1484, René N5 and CMSX-4. The research results of a low-Re third generation nickel-base single crystal superalloy are reported in this paper.

The goals of the present research were as follows: (1) develop a low-cost third generation single crystal superalloy, with low Re content; (2) acquire mechanical properties equivalent to the third generation single crystal superalloys, such as CMSX-10, René N6 and TMS-75; (3) design a superalloy combining high strength with good environmental properties, microstructural stability, heat treatment characteristics and castability. A low-cost third generation single crystal superalloy, designated as DD9, has been developed by Beijing Institute of Aeronautical Materials for advanced aeroengine blade applications.

\section{Alloy Design}

Re has a significant effect on improving the creep strength at elevated temperature and it is one of the most expensive elements in single crystal superalloys. As a result, decreasing the Re content will reduce alloy cost. The effects of Re on creep rupture life in the single crystal superalloy DD9 was studied. It was found in the study that Re can greatly improve the creep strength, and the total level of refractory elements such as W, Mo, Ta, Re and $\mathrm{Nb}$, also affects the creep strength in single crystal superalloys[17]. Therefore, it is suggested that not only the Re content has to be controlled but also the total refractory element level in single crystal superalloy should be selected correctly.

Using the previous studies of DD3, DD6 and DD9 single crystals and the help of the method of computer aided design of alloy compositions[22-24], the contents of tungsten, molybdenum, tantalum, rhenium and aluminum were judiciously balanced with the predominating rhenium requirement in the period of the 
Table I Nominal compositions of some typical three generations of single crystal superalloys (wt. \%)

\begin{tabular}{|c|c|c|c|c|c|c|c|c|c|c|c|c|c|c|c|}
\hline Element & $\mathrm{Cr}$ & Co & Mo & W & $\mathrm{Ta}$ & $\operatorname{Re}$ & $\mathrm{V}$ & $\mathrm{Nb}$ & $\mathrm{Al}$ & $\mathrm{Ti}$ & Hf & $\mathrm{C}$ & $\mathrm{Ni}$ & Density & Ref. \\
\hline Alloy & \multicolumn{13}{|c|}{ First Generation Single Crystals } & $\mathrm{kg} / \mathrm{cm}^{3}$ & \\
\hline PWA 1480 & 10 & 5 & - & 4 & 12 & - & - & - & 5.0 & 1.5 & - & - & Bal. & 8.70 & 1 \\
\hline René N4 & 9 & 8 & 2 & 6 & 4 & - & - & 0.5 & 3.7 & 4.2 & - & - & Bal. & 8.56 & 9 \\
\hline SRR 99 & 8 & 5 & - & 10 & 3 & - & - & - & 5.5 & 2.2 & - & - & Bal. & 8.56 & 10 \\
\hline CMSX-2 & 8 & 5 & 0.6 & 8 & 6 & - & - & - & 5.6 & 1.0 & - & - & Bal. & 8.56 & 11 \\
\hline \multirow[t]{2}{*}{ DD3 } & 9.5 & 5 & 4 & 5.5 & - & - & - & - & 5.8 & 2 & - & - & Bal. & 8.20 & 12 \\
\hline & \multicolumn{13}{|c|}{ Second Generation Single Crystals } & & \\
\hline PWA 1484 & 5 & 10 & 2 & 6 & 9 & 3 & - & - & 5.6 & - & 0.1 & - & Bal. & 8.95 & 2 \\
\hline René N5 & 7 & 7.5 & 1.5 & 5 & 7 & 3 & - & - & 6.2 & - & 0.15 & В 0.004 & Bal. & 8.63 & 13 \\
\hline CMSX-4 & 6.5 & 9 & 0.6 & 6 & 6.5 & 3 & - & - & 5.6 & 1 & 0.1 & - & Bal. & 8.70 & 14 \\
\hline \multirow[t]{2}{*}{ DD6 } & 4.3 & 9 & 2 & 8 & 7.5 & 2 & - & 0.5 & 5.6 & - & 0.1 & 0.006 & Bal. & 8.78 & 15,16 \\
\hline & \multicolumn{13}{|c|}{ Third Generation Single Crystals } & & \\
\hline René N6 & 4.2 & 12.5 & 1.4 & 6 & 7.2 & 5.4 & - & - & 5.75 & - & 0.15 & $\begin{array}{c}0.05 \\
\text { B } 0.004 \\
\text { Y } 0.01 \\
\end{array}$ & Bal. & 8.98 & 5,18 \\
\hline CMSX-10 & 2 & 3 & 0.4 & 5 & 8 & 6 & - & 0.1 & 5.7 & 0.2 & 0.03 & - & Bal. & 9.05 & 6,19 \\
\hline TMS-75 & 3 & 12 & 2 & 6 & 6 & 5 & - & - & 6 & - & 0.1 & - & Bal. & 8.89 & 20 \\
\hline DD9 & 3.5 & 7 & 2 & 6.5 & 7.5 & 4.5 & - & 0.5 & 5.6 & - & 0.1 & $\begin{array}{c}0.008 \\
Y 0.001\end{array}$ & Bal. & 8.96 & 21 \\
\hline
\end{tabular}

third generation single crystal superalloy development. A large number of trials were carried out, the compositions for DD9 alloy have been optimized to contain 4.5 wt. \% Re. On the basis of containing 4.5 wt. \% Re, a relatively high level of $\mathrm{W}+\mathrm{Mo}+\mathrm{Ta}+\mathrm{Re}+\mathrm{Nb}$ is employed to achieve the high creep strength exhibited by DD9, particularly at elevated temperatures. DD9 employs a relatively high concentration of refractory elements (W, Mo, Ta, Re and $\mathrm{Nb}$ ) of about 21 wt. \%; this in comparison to DD3 alloy which is about 9.5 wt. \% and to DD6 alloy which is about 20 wt. \%. Generally, the third generation single crystal superalloys contain 5-6 wt.\% Re. The Re content of DD9 alloy is about $75 \%, 83 \%$ and $90 \%$ of that of third generation single crystal superalloy CMSX-10, René N6 and TMS-75, respectively $[5,6,18-21]$. Thus an alloy cost reduction for DD9 is obtained.

Moreover, $\mathrm{W}$ and $\mathrm{Cr}$ tend to be involved in TCP phase formation. Utilizing high $\mathrm{W}$ content requires relatively low chromium alloying in DD9 alloy. Decreasing the $\mathrm{Cr}$ content will reduce the oxidation resistance of single crystal superalloy, in order to improve oxidation resistance, minor rare earth element $\mathrm{Y}$ was added into DD9 alloy. Based on the mechanical properties, TCP and microstructural stability, environmental resistance and castability of the candidate alloys, the nominal composition of DD9 alloy was finally selected.

The results of phase calculations of DD9 and critical value of the $\bar{M} d t$ (new phacomp), $\bar{M} d$ (new phacomp) and $\bar{N} v$ (phacomp) are listed in Table II. It has been demonstrated that alloy with lower value of the $\overline{M d t}, \overline{\mathrm{M} d}$ and $\overline{\mathrm{N}} \mathrm{v}$ than that of the critical values will show excellent microstructure stability with rarely existed topologically close-packed (TCP) phase [22-24]. The methods above mentioned are useful for predicating the formation of TCP in single crystal superalloy. It can be seen that DD9 have good microstructure stability based on the nominal compositions.
Table II Results of the phase calculation of DD9 alloy [22-24]

\begin{tabular}{|c|c|c|c|}
\hline Design parameters & $\begin{array}{c}\bar{M} d t \\
\text { of alloy }\end{array}$ & $\begin{array}{c}\bar{M} d \\
\text { of } \gamma \text { matrix }\end{array}$ & $\begin{array}{c}\bar{N} v \\
\text { of } \gamma \text { matrix }\end{array}$ \\
\hline DD9 Calculated value & 0.979 & 0.909 & 1.95 \\
\hline Critical value & 0.985 & 0.915 & 2.3 \\
\hline
\end{tabular}

Alloy Manufacture

Commercially pure raw materials for DD9 alloy were used for experimental study and commercial applications. The master alloy heat of DD9 was melted in a vacuum induction furnace according to the process set down by many experiments. The test bars, slabs and blades of DD9 alloy were cast in a directional solidification vacuum furnace.

\section{Microstructures}

\section{Microstructures and Heat Treatment}

The heating curves of as-cast alloy were obtained using differential scanning calorimeter (DSC), the heat treatment regime for DD9 alloy was carefully studied to provide acceptable microstructure and optimal mechanical properties. The test results show that DD9 alloy provides an attractive solution heat treatment capability, and the alloy is thereby able to be fully solutioned. The incipient melting of DD9 alloy occurs at $1352{ }^{\circ} \mathrm{C}$. The solution heat treatment, a $1335^{\circ} \mathrm{C}$ for 2 hours cycle, dissolves the coarse as-cast $\gamma^{\prime}$ and eutectic $\gamma-\gamma^{\prime}$ present in the alloy for reprecipitation into more fine $\gamma^{\prime}$, and the results mentioned above are shown in Figure 1. The heat treatment regime of DD9 alloy consists of a three-step process employing solution, primary aging and secondary aging heat treatments. The heat treatment regime of DD9 alloy is as follows: pre-heat treatment $+1340{ }^{\circ} \mathrm{C} / 6 \mathrm{~h} /$ Air Cool $+1120^{\circ} \mathrm{C} / 4 \mathrm{~h} / \mathrm{Air} \mathrm{Cool}+870^{\circ} \mathrm{C} / 32 \mathrm{~h} /$ Air Cool. Following the solution heat treatment cycle, primary aging and secondary 
aging heat treatments, are used to bond the MCrAlY coating and thermal barrier coating to the alloy, as well as to produce an optimum $\gamma^{\prime}$ size and distribution. The fully heat treated microstructures of DD9 alloy consist of approximately 68 vol. \% of cuboidal $\gamma^{\prime}$ precipitates with average edge dimension of about $0.4 \mu \mathrm{m}$ in $\gamma$ matrix, and the $\gamma^{\prime}$ phase fraction was determined from the mean value using ten specimens. The microstructures of fully heat treated DD9 alloy are shown in Figure 1.

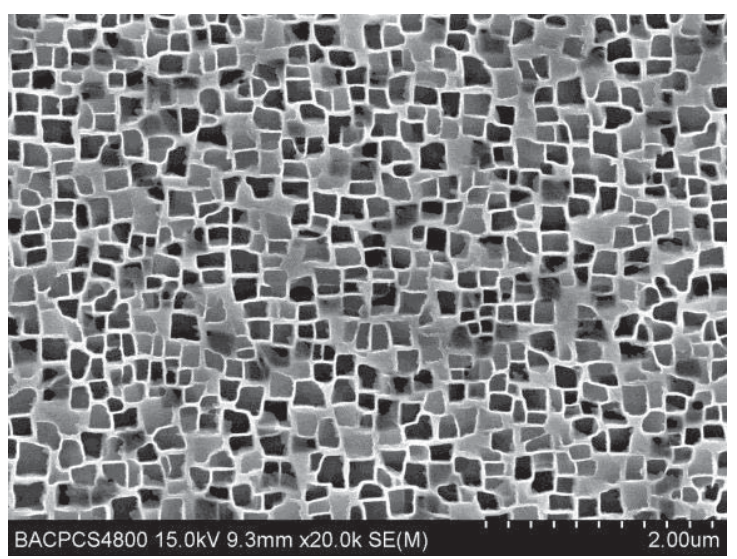

(a) as-solutioned at $1335^{\circ} \mathrm{C}$ for $2 \mathrm{~h}$

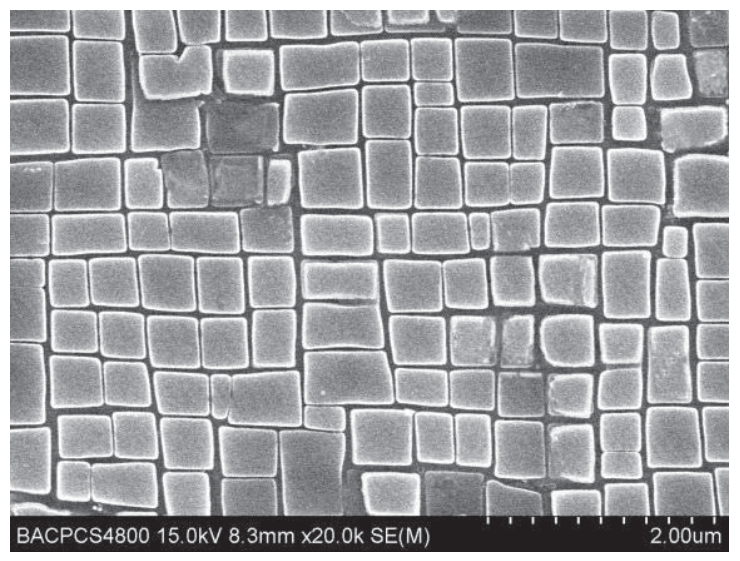

(b) fully heat treated

Figure 1. Microstructures of DD9 alloy in the as-solutioned at $1335^{\circ} \mathrm{C}$ for $2 \mathrm{~h}$ and fully heat treated.

\section{$\underline{\text { Microstructural Stability }}$}

The microstructure stability at elevated temperature was a key concern in the development of DD9 alloy. TCP phase formation is typically observed in many single crystal superalloys, especially those containing Re, although a small amount of TCP phase is not considered detrimental to the creep rupture and other properties of single crystal superalloys. The microstructures of DD9 alloy exposed at $980{ }^{\circ} \mathrm{C}$ for 2000 hours and 2500 hours are shown in Figure 2. The microstructure stability of DD9 alloy exposed at $980{ }^{\circ} \mathrm{C}$ for 2000 hours is excellent, no TCP phase precipitating, where a little TCP phase was found at $980{ }^{\circ} \mathrm{C}$ for 2500 hours. The microstructural stability of DD9 alloy is maintained by the reduction of rhenium content and keeping appropriate chromium content.

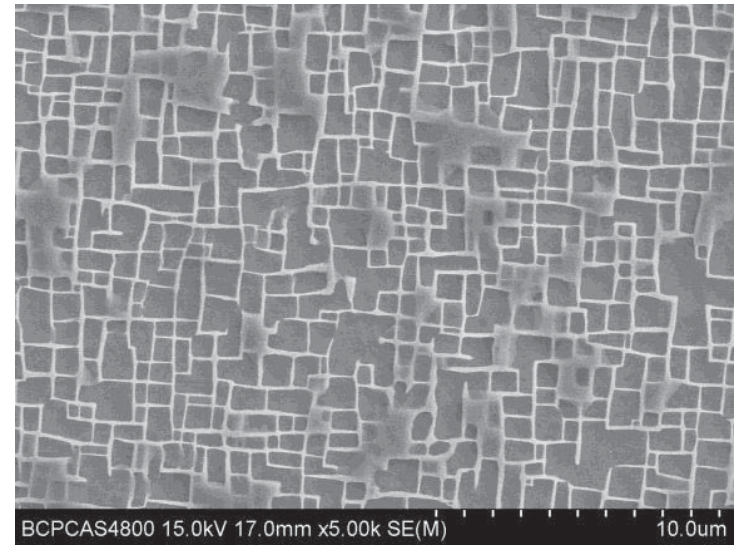

(a) 2000 hours

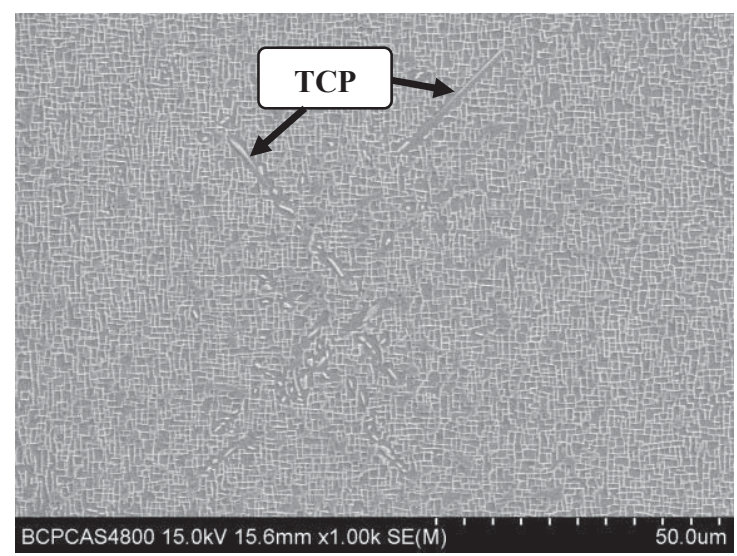

(b) 2500 hours

Figure 2. Microstructures of DD9 alloy exposed at $980{ }^{\circ} \mathrm{C}$ for 2000 hours and 2500 hours.

\section{Mechanical Properties}

\section{Tensile Properties}

The tensile properties of DD9 alloy were studied from room temperature to $1120{ }^{\circ} \mathrm{C}$ as shown in Figure 3. It can be seen that the ultimate tensile strength (UTS) and yield strength (YS) of DD9 alloy peak at about $760{ }^{\circ} \mathrm{C}$, while relatively good ductility is maintained throughout the tested regime from room temperature to $1120{ }^{\circ} \mathrm{C}$. The ultimate tensile strength and yield strength of DD9 at $760{ }^{\circ} \mathrm{C}$ is approximately $1277 \mathrm{MPa}$ and $1051 \mathrm{MPa}$, respectively. Table III and Figure 3 show a comparison of the yield strength of DD9 alloy with that of DD6 alloy. The yield strength of DD9 alloy offers an improvement compared with that of DD6 within range from room temperature to high temperature, especially the yield strength of DD9 is more than $88 \mathrm{MPa}$ relative to DD6 between $1070{ }^{\circ} \mathrm{C}$ and $1120^{\circ} \mathrm{C}$.

Table III Yield strength of DD6 and DD9 alloy [15, 21], MPa

\begin{tabular}{|c|c|c|c|c|c|c|c|}
\hline Temp., ${ }^{\circ} \mathrm{C}$ & 20 & 650 & 760 & 980 & 1070 & 1100 & 1120 \\
\hline DD6 & 929 & 965 & 993 & 680 & 440 & 385 & 318 \\
\hline DD9 & 1033 & 1028 & 1051 & 710 & 551 & 482 & 406 \\
\hline
\end{tabular}




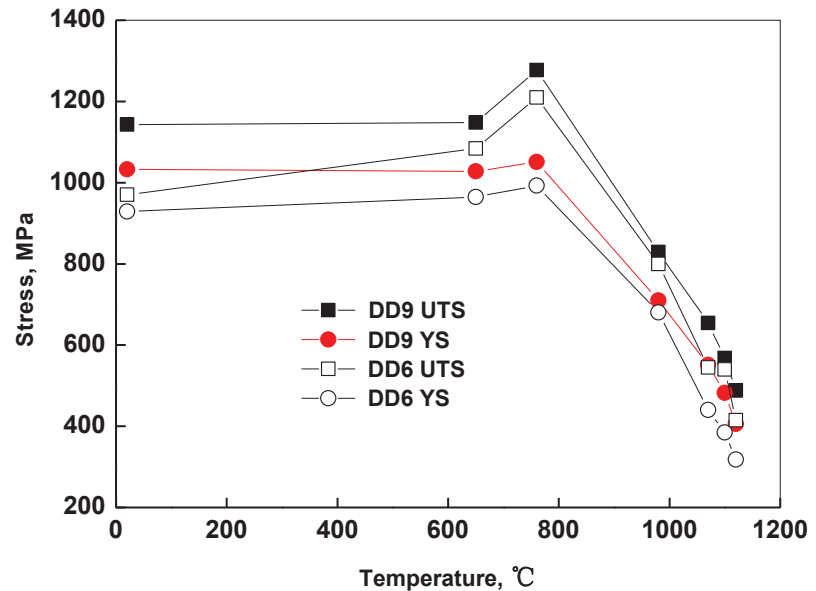

Figure 3. Ultimate tensile strength and yield strength of DD6 and DD9 alloy $[15,21]$

\section{Creep Rupture Properties}

The creep rupture properties of DD9 alloy have been extensively characterized in a series of tests between $650{ }^{\circ} \mathrm{C}$ and $1130{ }^{\circ} \mathrm{C}$. Figure 4 shows the creep curves of DD6 and DD9 alloy at $980{ }^{\circ} \mathrm{C} /$

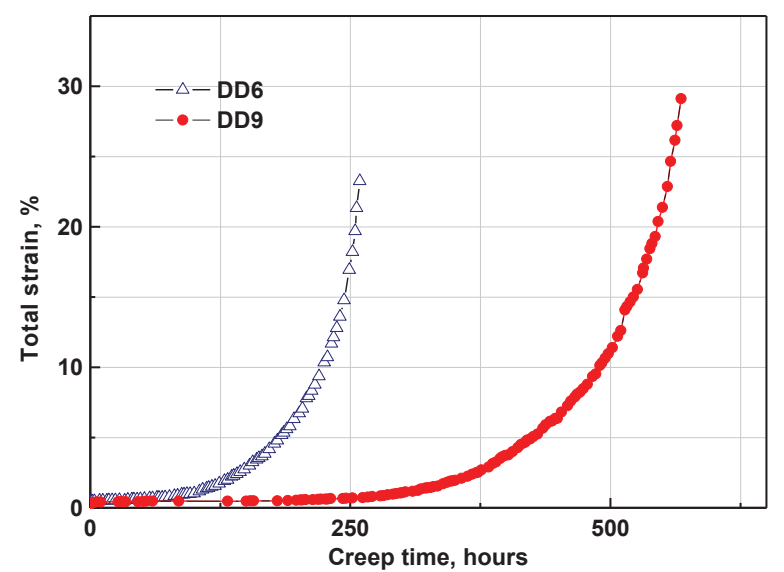

Figure 4. Creep curves of DD6 and DD9 alloy at $980{ }^{\circ} \mathrm{C} / 250 \mathrm{MPa}$.

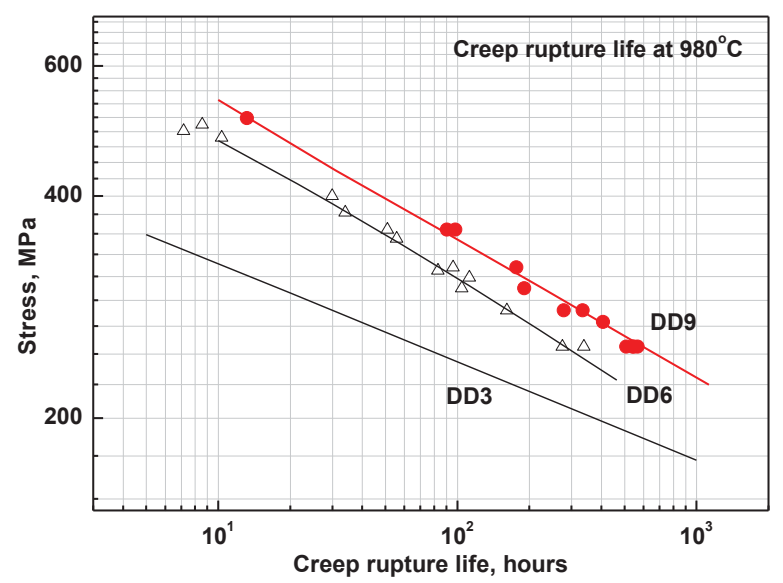

Figure 5. Creep strength of DD3, DD6 and DD9 alloy at $980{ }^{\circ} \mathrm{C}$.
$250 \mathrm{MPa}$ and the rate of primary and secondary creep of DD9 alloy is very slow. Figure 5 shows the creep strength of DD3, DD6 and DD9 alloy at $980{ }^{\circ} \mathrm{C}$, and the creep rupture life of DD6 and DD9 alloy is 275 hours and 568 hours at $980{ }^{\circ} \mathrm{C} / 250 \mathrm{MPa}$, respectively.

The creep rupture properties are summarized in Figure 6 showing a Larson Miller Parameter comparison between DD3, DD6, DD9, CMSX-10Ia and TMS-75 [12, 15, 19, 20]. The creep rupture life of DD9 at the conditions of $1100^{\circ} \mathrm{C} / 137 \mathrm{MPa}$ and $1130^{\circ} \mathrm{C} / 137 \mathrm{MPa}$ is about 274 hours and 110 hours, respectively. DD9 alloy possesses greater creep strength than DD6 from $650^{\circ} \mathrm{C}$ to $1130^{\circ} \mathrm{C}$ especially at elevated temperature, and the advantage of DD9 in creep rupture life at $1100{ }^{\circ} \mathrm{C} / 137 \mathrm{MPa}$ is about 126 hours relative to DD6 alloy [15]. Apparently, the improvement of the creep strength of the third generation single crystal superalloy DD9 relative to the second generation single crystal superalloy DD6 is lower than that of DD6 relative to the first generation single crystal superalloy DD3.

CMSX-10Ia is chosen to represent CMSX-10 alloy, because the compositions of CMSX-10Ia is the most similar to those of CMSX-10 alloy among all the test materials [19]. The creep rupture life of DD6 alloy, the third generation single crystal superalloy TMS-75 and DD9 at $1100{ }^{\circ} \mathrm{C} / 137 \mathrm{MPa}$ is shown in

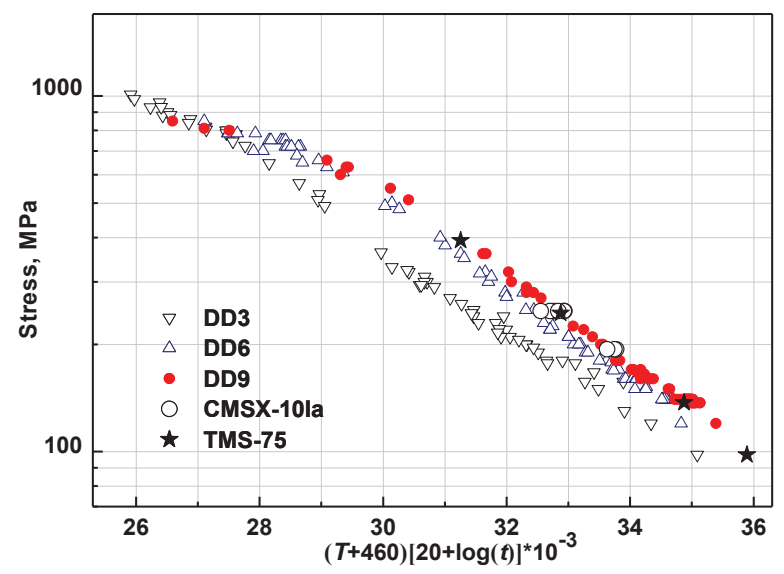

Figure 6. Larson-Miller creep strength of DD3, DD6, DD9, CMSX-10Ia and TMS-75 alloy [12, 15, 19, 20].

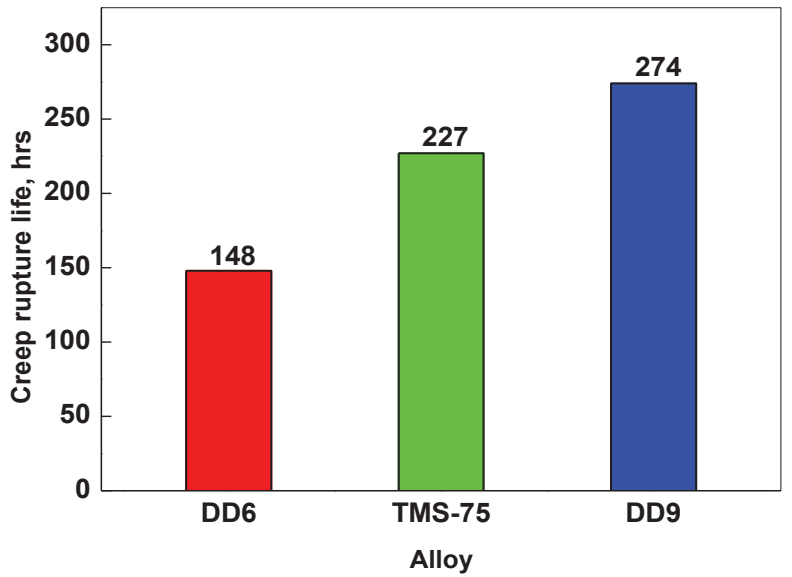

Figure 7. Creep rupture life of DD6, TMS-75 and DD9 alloy at $1100{ }^{\circ} \mathrm{C} / 137 \mathrm{MPa}[15,20]$. 
Figure $7[15,20]$, and the data of DD6 and DD9 is the average value of test respectively, while that of TMS-75 is collected from the report [20]. The creep strength of DD9 alloy is at least equivalent to those of other third generation single crystal superalloys in the world, such as CMSX-10 and TMS-75, even better in certain conditions as shown in Figure 6 and Figure 7. Figure 8 shows the microstructures of the creep tests interrupted after 80 hours of DD6 and DD9 alloy at $980{ }^{\circ} \mathrm{C} / 250 \mathrm{MPa}$. The rafting of DD6 alloy fully forms in the whole specimens and the cuboidal $\gamma^{\prime}$ disappears, while the rafting of DD9 alloy forms in the most specimens and some $\gamma^{\prime}$ still keeps cuboidal in certain degree. The results mentioned above demonstrate the microstructure stability of DD9 alloy is superior to that of DD6 alloy at high temperature. The improvement of the creep strength of DD9 relative to DD6 is mainly attributable to the high refractory element contents and the fully exploring of the strengthening potential of solution hardening and precipitation hardening.

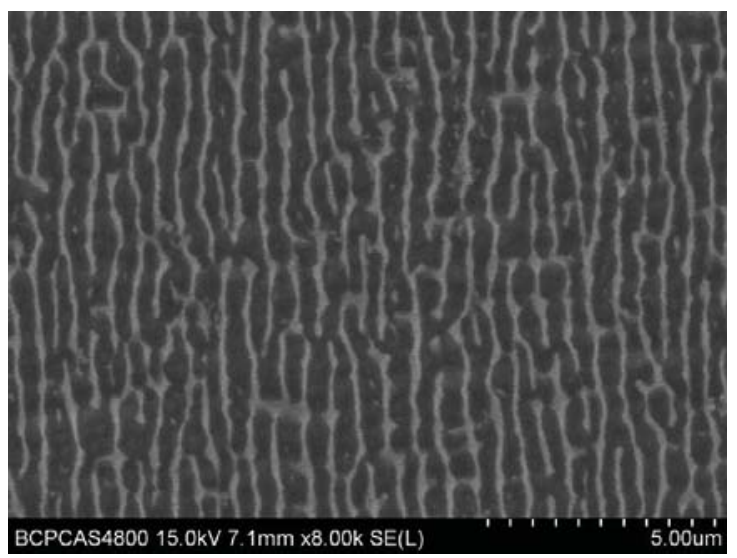

(a) DD6 alloy

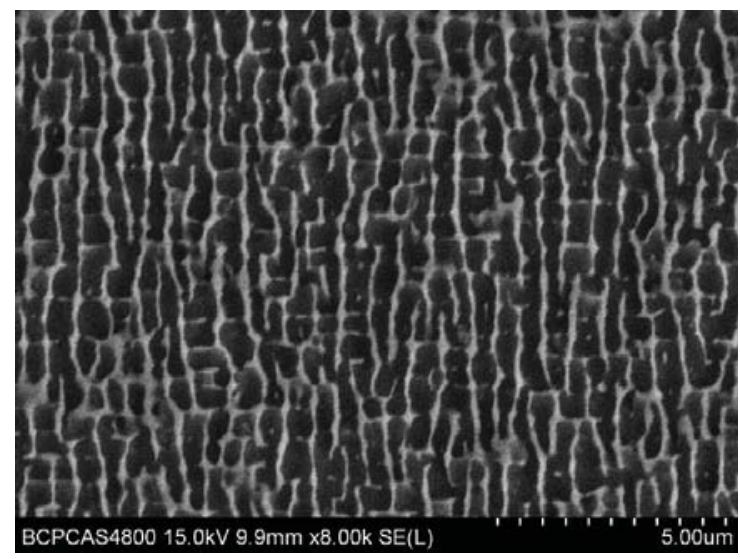

(b) DD9 alloy

Figure 8. Microstructures of the creep tests interrupted after 80 hours of DD6 and DD9 alloy at $980{ }^{\circ} \mathrm{C} / 250 \mathrm{MPa}$

\section{$\underline{\text { Fatigue }}$}

High cycle fatigue tests have been performed for DD9 alloy. The advantage of DD9 shown in the creep rupture properties over DD6 alloy generally holds for the fatigue properties. For $10^{7}$ cycle smooth high cycle fatigue (HCF), the high cycle fatigue strength of DD9 and DD6 alloy is $428 \mathrm{MPa}$ and $382 \mathrm{MPa}$ at $800{ }^{\circ} \mathrm{C}$ respectively, therefore DD9 alloy provides a $46 \mathrm{MPa}$ advantage relative to DD6 alloy in the uncoated condition, the alloy exhibits excellent HCF capability overall, especially at higher temperatures.

\section{Environmental Properties}

Oxidation resistance

The tests of the environmental resistance of DD9 alloy were undertaken by both burner rig and crucible (static) evaluation methods, and the tests of the oxidation resistance of DD9 alloy were performed at $1100{ }^{\circ} \mathrm{C}$. The weight change rates of the oxidation resistance tests of the specimens of DD9 and DD6 at $1100{ }^{\circ} \mathrm{C}$ for 100 hours in the uncoated conditions by the crucible method, are presented in Table IV. The appearances of the specimens of the oxidation resistance for DD6 and DD9 tested by crucible method at $1100{ }^{\circ} \mathrm{C}$ for 100 hours are shown in Figure 9.

Table IV Oxidation resistance of DD9 and DD6 at $1100{ }^{\circ} \mathrm{C}$ for 100 hours

\begin{tabular}{|c|c|c|}
\hline Alloy & DD9 & DD6 \\
\hline Weight change rate, $\mathrm{g} /\left(\mathrm{m}^{2} \cdot \mathrm{h}\right)$ & 0.034 & 0.049 \\
\hline
\end{tabular}
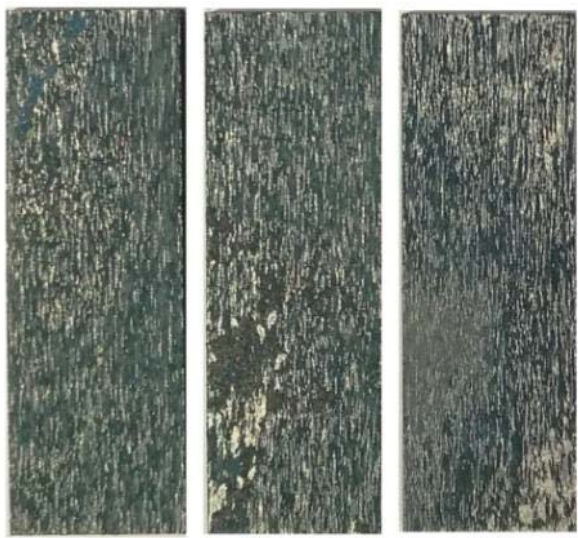

DD6
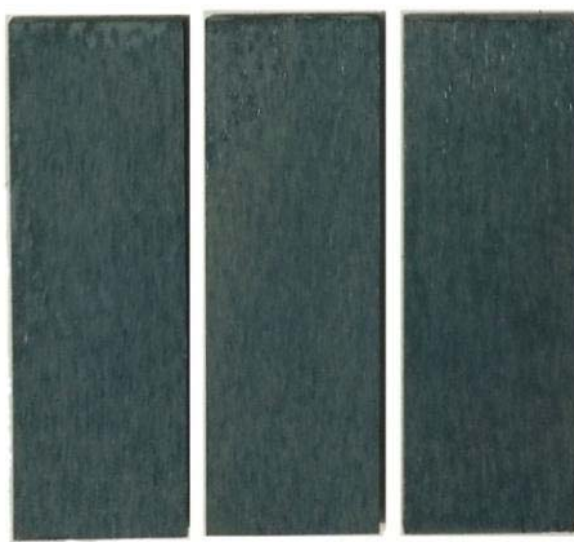

DD9

$1 \mathrm{~cm}$

Figure 9. Appearances of the specimens of the oxidation resistance for DD6 and DD9 alloy tested by crucible method at $1100{ }^{\circ} \mathrm{C}$ for 100 hours. 
DD9 alloy exhibits very good oxidation resistance for the duration of the test, and the oxidation resistance of DD9 alloy is improvement relative to that of DD6 alloy. The excellent oxidation resistance of DD9 alloy is attributable to its $\mathrm{Y}$ content compared to DD6 that contains no Y, despite the Cr level of DD9 being about $20 \%$ lower than DD6.

\section{$\underline{\text { Hot corrosion resistance }}$}

Table V lists the hot corrosion resistance properties of DD9 and DD6 alloy at $900{ }^{\circ} \mathrm{C}$ for tested 100 hours in uncoated conditions by the burner rig method [15]. The actual test results are presented in terms of the weight change rates of the specimens. The salt content in the hot corrosion resistance test was $0.002 \%$, and the weight change rate of the hot corrosion resistance of DD9 alloy at $900{ }^{\circ} \mathrm{C}$ for 100 hours was basically equivalent to that of DD6. The superior hot corrosion resistance properties of DD9 alloy are attributed to the fact that the alloy has optimum compositions. Tantalum positively influences environmental properties, therefore Ta level of about 7.5 wt. \% is employed in DD9 alloy system.

Table V Hot corrosion resistance of DD9 and DD6 alloy at $900{ }^{\circ} \mathrm{C}$ for 100 hours [15]

\begin{tabular}{|c|c|c|}
\hline Alloy & DD9 & DD6 \\
\hline Weight change rate, $\mathrm{g} /\left(\mathrm{m}^{2} \cdot \mathrm{h}\right)$ & 0.0393 & 0.0530 \\
\hline
\end{tabular}

The MCrAlY coating was applied to DD9 alloy successfully. For a $10^{7}$ cycle at $800^{\circ} \mathrm{C}$, the smooth high cycle fatigue life of DD9 alloy with MCrAlY coating is approximately equal to that of the alloy in uncoated condition. The applications of environmental coating may further improve the oxidation and hot corrosion resistance of DD9 alloy.

\section{Castability}

The casting trials have been conducted on DD9 alloy involving a great number of test slabs, bars, several different complex shaped hollow turbine blades and double wall cooling blades. Such double wall cooling blades are extremely difficult to produce in directional castings because of the small dimensions and fragility of the ceramic core. One of the difficulties is for forming channels approximately $0.8 \mathrm{~mm}$ deep by $0.75 \mathrm{~mm}$ wide on the outer surface of the casting that eventually serve as the cooling channels between the double walls. The results of the detailed inspections for the crystal quality by X-ray technology and casting yields obtained in these trials were similar to other second generation single crystal superalloys. These trials demonstrated that DD9 alloy is not prone to the formation of single crystal process anomalies such as freckles and slivers, thus the alloy possesses excellent single crystal castability. The castability of DD9 alloy is enhanced by alloy design. Since tantalum has a beneficial effect on single crystal castability in reducing alloy freckle formation, the Ta: $\mathrm{W}$ ratio is regulated for beneficial effects.

\section{Summary}

A low-cost third generation single crystal superalloy, designated as DD9, has been developed. Based on the study of a series of single crystal superalloys for thirty years, with the help of the method of computer aided design alloy composition, the contents of tungsten, molybdenum, tantalum, rhenium and aluminum were judiciously balanced with the predominating rhenium requirement during DD9 development. DD9 alloy contains 4.5 wt. \% Re, and the alloy system employs relatively high refractory element (W, Mo, Ta, Re and $\mathrm{Nb}$ ) content of about 21 wt. \%. The Re content of DD9 alloy is about $75 \%, 83 \%$ and $90 \%$ of that of third generation single crystal superalloy CMSX-10, René N6 and TMS-75, respectively. Thus a cost reduction for DD9 alloy is achieved.

Apparently, the improvement of the creep strength of the third generation single crystal superalloy DD9 relative to the second generation single crystal superalloy DD6 is lower than that of DD6 relative to the first generation single crystal superalloy DD3. DD9 alloy has an approximate $30{ }^{\circ} \mathrm{C}$ improvement of temperature capability relative to DD6 alloy. The creep strength of DD9 alloy are equivalent to those of the other third generation single crystal superalloys in the world, such as CMSX-10 and TMS-75, even better in certain conditions. Most notably, the advantage of DD9 alloy shown in the creep rupture properties over DD6 alloy generally holds for the fatigue properties.

DD9 alloy also provides excellent oxidation resistance and hot corrosion resistance properties. In addition, the microstructural stability of DD9 at elevated temperature after long term exposure is maintained. DD9 alloy also has satisfactory heat treatment characteristics, castability and coatability.

\section{$\underline{\text { References }}$}

1. M. Gell, D.N. Duhl and A.F. Giamei, "The Development of Single Crystal Superalloy Turbine Blades", Superalloys 1980, ed. J.K. Tien et al., (Metals Park, OH: American Society for Metals, 1980), 205-214.

2. A.D. Cetel and D.N. Duhl, "Second Generation Nickel-Base Single Crystal Superalloy", Superalloys 1988, ed. S. Reichman et al., (Warrendale, PA: The Metallurgical Society, 1988), 235-244.

3. K. Harris et al., "Development of the Rhenium Containing Superalloys CMSX-4 and CM186LC for Single Crystal Blade and Directionally Solidified Vane Applications in Advanced Turbine Engines", Superalloys 1992, ed. S.D. Antolovich et al., (Warrendale, PA: TMS, 1992), 297-306.

4. E.W. Ross and K.S. O'Hara, "René N4: A First Generation Single Crystal Turbine Airfoil Alloy with Improved Oxidation Resistance, Low Angle Boundary Strength and Superior Long Time Rupture Strength", Superalloys 1996, ed. R.D. Kissinger et al., (Warrendale, PA: TMS, 1996), 19-25.

5. W.S. Walston, K.S. O'Hara and E.W. Ross, et al., "Rene'N6: Third Generation Single Crystal Superalloy", Superalloys 1996, ed. R.D. Kissinger et al., (Warrendale, PA: TMS, 1996), 27-34.

6. G.L.Erickson, "The Development and Application of CMSX10", Superalloys 1996, ed. R.D. Kissinger et al., (Warrendale, PA: TMS, 1996), 35-44. 
7. B.B. Seth, "Superalloys-The Utility Gas Turbine Perspective", Superalloys 2000, ed. T.M. Pollock et al., (Warrendale, PA: TMS, 2000), 3-16.

8. S. Walston et al., "Joint Development of a Fourth Generation Single Crystal Superalloy", Superalloys 2004, ed. K. A. Green et al., (Warrendale, PA: TMS, 2004), 15-24.

9. J.W. Holmes and K.S. O'Hara, ASTM STP 942, (Philadelphia, PA: ASTM, 1988), 672-691.

10. D.A. Ford and R.P. Arthey, "Development of Single Crystal Alloys for Specific Engine Application”, Superalloys 1984, ed. M. Gell et al., (Warrendale, PA: TMS, 1984), 115-124.

11. K. Harris and G.L. Erickson, Cannon-Muskegon Corporation, U. S. patent 4,582,548-CMSX-2 Alloy.

12. Wu Zhongtang, Wen Zhongyuan and Chen Dehou, "Composition Design and Experimental Study of Single Crystal Alloy DD3”, Acta Metallurgica Sinica, 23(4), (1987), B171-B178.

13. C.S. Wukusick and L. Buchakjian, U. K. Patent Appl. GB2235697, "Improved Property Balanced Nickel-base Superalloys for Producing Single Crystal Articles"-René N5 Alloy.

14. K. Harris and G.L. Erickson, Cannon-Muskegon Corporation, U. S. patent 4,643,782-CMSX-4 Alloy.

15. J.R. Li, Z.G. Zhong, D.Z. Tang and S.Z. Liu et al., "A LowCost Second Generation Single Crystal Superalloy DD6", Superalloys 2000, ed. T.M. Pollock et al., (Warrendale, PA: TMS, 2000), 777-783.

16. J.R. Li, J.Q. Zhao, S.Z. Liu and M. Han, "Effects of Low Angle Boundaries on the Mechanical Properties of Single Crystal Superalloy DD6", Superalloys 2008, ed. R.C. Reed et al., (Warrendale, PA: TMS, 2008), 443-451.

17. Jiarong Li, Dingzhong Tang, Riling Lao et al., "Effects of Rhenium on Creep Rupture Life of a Single Crystal Superalloy", Journal of Materials Science and Technology, 15(1), (1999), 53-57.

18. W.S. Walston, E.W. Ross, K.S. O'Hara and T.M. Pollock, General Electric Company, U. S. patent 5,270,123-RenéN6 Alloy.

19. G.L.Erickson, Cannon-Muskegon Corporation, U.S. patent 5,366,695-CMSX-10 Alloy.

20. High Temperature Materials Center, National Institute for Materials Science (NIMS), Japan, "Third Generation Nickel Base Single Crystal Superalloy TMS-75”, July, 2006, http://sakimori.nims.go.jp.

21. Wang Xiaoguang, Li Jiarong and Yu Jian, et al., "Tensile Anisotropy of Single Crystal Superalloy DD9", Acta Metallurgica Sinica, 51(10), (2015), 1253-1260.
22. R.G. Barrows and J.B. Newkirk, "A Modified System for Predicting $\sigma$ Formation”, Metallurgical Transactions, 3(11), (1972), 2889-2893.

23. K. Matsugi, Y. Murata and M. Morinaga, "An Electronic Approach to Alloy Design and Its Application to NickelBased Single Crystal Superalloys", Materials Science and Engineering, 172A, (1993), 101-110.

24. M. Morinaga, Y. Murata and H. Yukawa, "An Electronic Approach to Materials Design", Journal of Material Science and Technology, 19(Suppl.1), (2003), 73-76. 